Chronic Obstructive Pulmonary Diseases: Journal of the COPD Foundation

Review

\title{
Inhalation Technique Errors with Metered-Dose Inhalers Among Patients with Obstructive Lung Diseases: A Systematic Review and Meta-Analysis of U.S. Studies
}

Soojin Cho-Reyes, $\mathrm{PhD}^{1}$ Bartolome R. Celli, MD, FCCP ${ }^{2}$ Carole Dembek, $\mathrm{MS}^{3}$ Karen Yeh, BS ${ }^{1}$ Maryam Navaie, DrPH, MBA ${ }^{1,4}$

\begin{abstract}
Background: Metered dose inhalers (MDIs) are commonly prescribed for inhalation therapy, but correct use is critical to promoting effective medication delivery. This systematic literature review and meta-analysis evaluates the overall and step-by-step prevalence of errors among adults with obstructive lung diseases in the United States who used MDIs.

Methods: Electronic and manual searches conducted between 1979-2018 using PubMed, EMBASE, PsycINFO, Cochrane, and Google identified 10 articles that met the following inclusion criteria: (a) English language, (b) U.S. adults diagnosed with chronic obstructive pulmonary disease, and (c) MDI use error rates. Meta-analytic techniques using random-effects models were applied to calculate effect sizes, weighted proportions, and $95 \%$ confidence intervals (CIs). Heterogeneity was assessed by the $\mathrm{I}^{2}$ statistic.

Results: Aggregate findings revealed that $86.7 \%$ of patients ( $\mathrm{n}=390,95 \%$ CI 77.5-96.0) made at least 1 inhalation technique error, and $76.9 \%(n=885,95 \%$ CI $65.8-87.9)$ incorrectly performed $\geq 20 \%$ of device use steps. The most prevalent step-by-step errors across the studies $(n=1105)$ were failure to: (a) exhale fully and away from the inhaler before inhalation (65.5\% [95\% CI 52.0, 78.9]); (b) hold breath for 5-10 seconds (41.9\% [95\% CI 29.8, 53.9]); (c) inhale slowly and deeply (39.4\% [95\% CI 26.2, 52.5]); (d) exhale after inhalation (35.9\% [95\% CI 17.0, 54.8]); and (e) shake the inhaler before use (34.2\% [95\% CI 30.6, 37.7]).

Conclusions: Across the studies used in this meta-analysis more than three-fourths of U.S. adults with obstructive lung diseases used MDIs incorrectly. Our findings suggest the need for ongoing patient education and consideration of alternative devices to mitigate errors.
\end{abstract}

\footnotetext{
Abbreviations: metered-dose inhaler, MDI; confidence interval, CI; chronic obstructive pulmonary disease, COPD; meta-analysis, MA; systematic literature review, SLR; number, $\mathbf{N}$; randomized controlled trial, RCT; prospective observational, PO; cross-sectional, CS; MDI with spacer, $\mathbf{M D I}+\mathbf{S}$; male, $\mathbf{M}$; female, $\mathbf{F}$

Funding Support: Sunovion Pharmaceuticals Inc.

Date of Acceptance: April 28, 2019

Citation: Cho-Reyes S, Celli BR, Dembek C, Yeh K, Navaie M. Inhalation technique errors with metered-dose inhalers among patients with obstructive lung diseases: a systematic review and meta-analysis of U.S. studies. Chronic Obstr Pulm Dis. 2019;6(3):267-280. doi: https:// doi.org/10.15326/jcopdf.6.3.2018.0168
}

\section{Advance Health Solutions, LLC, New York, New York}

2 Harvard Medical School, Boston, Massachusetts and Chronic Obstructive Pulmonary Disease Center, Brigham and Women's Hospital, Boston, Massachusetts
3 Global Health Economics and Outcomes Research, Sunovion Pharmaceuticals, Inc., Marlborough, Massachusetts

4 Columbia University, School of Professional Studies, New York, New York 


\section{Address correspondence to:}

Maryam Navaie, DrPH, MBA

Chief Global Strategy Officer

Advance Health Solutions, LLC

5 Penn Plaza, 23rd Floor

New York, NY 10001

Phone: (212) 835-1510

E-mail: mnavaie@advancehealthsolutions.com

\section{Keywords:}

systematic literature review; meta-analysis; chronic obstructive pulmonary disease; COPD; asthma; inhaler errors; inhalation technique; handheld inhalers; metered-dose inhaler errors; MDI errors; nebulizers; inhaler education

Note: An earlier version of this manuscript was presented, in part, at the annual conference of the American College of Chest Physicians, October 6-10, 2018 in San Antonio, Texas.

\section{Introduction}

In the United States, the most prevalent obstructive lung diseases are asthma and chronic obstructive pulmonary disease (COPD). ${ }^{1,2}$ Taken together, these conditions are a leading cause of morbidity and mortality among U.S. adults. ${ }^{2,3}$ An estimated 16.5 million Americans are diagnosed with asthma, 16 million with COPD, and 0.94 million with asthmaCOPD overlap syndrome. ${ }^{1-4}$ The economic burden of asthma and COPD is substantial. The costs of treating asthma range between $\$ 56$ billion ${ }^{5}$ and $\$ 81.9$ billion, ${ }^{6}$ of which $61 \%$ is associated with medical costs. ${ }^{6}$ The health care costs of COPD are similarly staggering, accounting for more than $\$ 72.7$ billion yearly. ${ }^{7}$

Although neither asthma nor COPD can be cured, both can be managed through inhaled bronchodilators that deliver aerosolized medications into the lungs. A range of inhaler devices can be used to administer bronchodilators including metered-dose inhalers (MDIs), dry powder inhalers, soft mist inhalers, and nebulizers. ${ }^{8}$ MDIs are the most commonly used handheld devices, ${ }^{9}$ but they require patients to have good hand-breath coordination so they can simultaneously manage breathing and actuation for effective drug delivery. ${ }^{10}$ As a result, MDIs are considered to be inherently more difficult to administer than alternative devices. ${ }^{11}$ The importance of proper inhaler technique cannot be over emphasized. Past research has shown that incorrect inhaler technique may compromise medication delivery, ${ }^{12-14}$ resulting in poor outcomes over time including increased risk of exacerbations, higher health resource utilization, and mortality. ${ }^{13-17}$

Difficulty using MDIs has long been documented in the literature. In 2001, a meta-analysis (MA) of 24 studies found that nearly $77 \%$ of international (nonU.S.) patients with asthma or COPD made at least 1 error while using MDIs. ${ }^{18}$ More recently, another internationally-focused MA study reported that $86.8 \%$ of patients with asthma or COPD made errors using an MDI, $45.6 \%$ of which were considered to be critical (errors that would directly impact the effectiveness of the drug). ${ }^{11}$ In an attempt to facilitate MDI use, a spacer is often recommended. ${ }^{8,19}$ However, to date, there is little evidence that shows the use of a spacer actually reduces inhalation technique errors. Indeed, more than $60 \%$ of patients, on average, have been reported to continue having difficulty using MDIs correctly even with a spacer. ${ }^{20-24}$

The extent and type of inhalation technique errors with MDIs have been synthesized among patients in diverse international settings through previous narrative reviews, ${ }^{25-30}$ systematic literature reviews (SLRs), ${ }^{12,31-37}$ and MA studies. ${ }^{11,17,38}$ However, none of these past studies conducted a step-by-step MA of errors to identify the device use steps patients found to be the most challenging. Moreover, the study populations in previous MA studies have been predominantly globally focused, with limited attention on U.S. patients. Individual studies on U.S. populations with obstructive lung diseases have shown that the proportion of patients making at least 1 inhalation technique error or errors in $\geq 20 \%$ of MDI device use steps ranges between $65 \%$ to $100 \% .^{21-24,39-41}$ However, drawing inferences from these studies is limited due to the relatively small sample sizes and heterogeneity across populations, error definitions, care settings, and diagnoses. To date, there has been no comprehensive study combining an SLR and MA on MDI errors in U.S. patients to evaluate the prevalence and types of errors.

Differences between U.S. and international patients with obstructive lung diseases have been documented with regards to sociodemographic characteristics (e.g., education and/or literacy levels), ${ }^{42-44}$ comorbidities and pulmonary disease severity. ${ }^{19,29,42,45}$ In addition, differences in health system factors (e.g., payer source and physician training) have been reported to play a role in disease management among U.S. and non-U.S. 
patients with lung disease. ${ }^{19,26,29,45}$ These differential attributes can influence the patient's ability to properly use MDIs. ${ }^{35,42,46}$ Therefore, synthesized findings based on international populations may not be directly generalizable to U.S. patients. The purpose of this study was 2 -fold: (a) to quantify the prevalence of inhalation technique errors among U.S. adults with COPD who use MDIs, and (b) to determine which device use steps were the most problematic for patients using MDIs.

\section{Methods}

\section{Search Strategy}

An SLR was conducted using PubMed, EMBASE, PsycINFO, Cochrane, and Google Scholar. We identified studies published from January 1, 2010 to November 15, 2018 that met the following criteria: (a) English language; (b) U.S. adults diagnosed with COPD; and (c) information available on MDI errors. In a few articles, authors combined patients diagnosed with COPD, asthma, or other chronic obstructive disease into a single group and presented their results on this combined study population. Thus, while we restricted our search criteria to COPD patients, if a publication combined COPD with other diagnoses of obstructive lung disease, that study would have been identified by our search and evaluated further.

The following data were extracted from the studies: (a) patients' sociodemographic characteristics (e.g., age, sex, health literacy level); (b) primary diagnosis; and (c) inhalation technique and step-by-step device use errors. In addition to electronic searches, a manual search was conducted covering the period of January 1, 1979 to November 15, 2018 by reviewing all of the references contained within the articles identified from electronic searches.

\section{Quality Assessment}

Study quality was graded by 3 trained independent reviewers. Studies that met the following criteria were classified as poor quality and excluded from the MA: (a) combined error rates across multiple devices; (b) reported error rates for $\leq 5$ patients; and (c) if there was no way to ascertain the percentage of patients who made inhalation technique errors from the data provided. For randomized controlled trials, quality was assessed using criteria published by the Cochrane Collaborative. ${ }^{47}$ For cross-sectional and observational studies, quality was assessed using applicable scales by Newcastle and Ottawa. ${ }^{48}$

\section{Metered-Dose Inhaler Device Use Steps}

Reported errors were based on the patients' ability to correctly complete the following 12 device use steps: (1) removing the cap; (2) shaking the inhaler before use; (3) attaching the inhaler to a spacer, as needed; (4) holding the inhaler upright; (5) exhaling completely (and away from the inhaler) before inhalation; (6) placing the inhaler mouthpiece between teeth and sealing lips; (7) actuating once during inhalation; (8) inhaling slowly and deeply; (9) holding breath for 5-10 seconds; (10) removing the inhaler or spacer from the mouth; (11) exhaling and breathing normally; and (12) repeating steps for a second puff. These steps were the most frequently reported across the 10 studies evaluated in this MA. Additional steps that were reported in only 1 study (e.g., checking expiration date and priming device) ${ }^{49}$ were not analyzed. For the purposes of step-by-step device use error analysis, all steps were included with the exception of 1 and 4 due to limited data availability.

\section{Statistical Analysis}

The proportion of MDI device use errors was analyzed using the following 2 definitions depending on data availability: (1) the percentage of patients who made at least 1 inhalation technique error $24,41,46,49,50$; or (2) the percentage of patients who incorrectly performed $\geq 20 \%$ of device use steps. ${ }^{21-24,40}$ For one study, ${ }^{39}$ the percentage of patients with at least 1 inhalation technique error was inferred based on the reported device use step with the highest frequency of error. For studies that reported inhalation technique errors for both pre- and post-interventions, only pre-intervention (i.e., baseline) error data were used for both control and intervention groups. Step-by-step device use errors were also analyzed. For studies that presented error data graphically, numeric values were estimated by interpreting graphic representations and validated by 2 independent analysts. Additional calculations were performed as follows, depending on selected scenarios: (1) if authors presented the percentage of patients who performed each step correctly, results were converted to the percentage of patients who performed each step incorrectly; (2) if authors reported 2 error rates for each device use step, a mean value was computed; 
and (3) if authors reported error rates for 2 different subgroups instead of their entire study population, weight means were calculated based on the proportion of each subgroup.

\section{Meta-Analysis}

Information about the prevalence of overall inhalation technique errors as well as step-by-step device use errors was gathered according to the recommendations outlined by the "Meta-analysis of Observational Studies in Epidemiology" guidelines ${ }^{51}$ for MA and systematic reviews. Pooled estimates (weighted proportions) and 95\% confidence intervals (CIs) were computed using the approximation of a binomial distribution. ${ }^{52}$ To visually inspect the degree to which the effect estimates of each study distributed around the pooled effect estimates, forest plots were created for pooled and step-by-step device use errors. Heterogeneity was assessed by the $\mathrm{I}^{2}$ statistic to determine the suitability of combining estimates across studies. ${ }^{53,54} \mathrm{I}^{2}$ values of $25 \%, 50 \%$, and $75 \%$, corresponded to small, moderate, and large degree of heterogeneity. ${ }^{55}$ Given the small number of studies, we performed a restricted maximum likelihood random-effects model using JASP 9.2 software. ${ }^{54,55}$

\section{Results}

\section{Search Results}

A total of 615 potential publications met the initial screening criteria (Figure 1). The manual search identified an additional 22 publications. After removing duplicate studies $(n=193), 444$ abstracts were evaluated further to determine relevance. After eliminating 349 abstracts that did not meet the eligibility criteria, 95 full-text articles remained and were reviewed in detail. Among these articles, 85 studies did not have data on U.S. adults or MDI device errors, resulting in a total of 10 publications that were included in this MA.

\section{Patient Characteristics}

There were 1360 patients included across the 10 studies (Table 1). The range in the average age of the patients was from 38 to 82 years. More than half of the patients were female (54\%) and nearly three-quarters (74\%) had a COPD diagnosis. Between $9 \%$ to $37 \%$ of patients had low health literacy (based on reports from 7 studies). Due to use of multiple devices and participants who did not complete the entire study cycle, MDI errors were reported for a total of 1275 patients, $27.6 \%(n=352)$ of whom also used a spacer.

\section{Inhalation Technique Errors Using Metered- Dose Inhalers}

Aggregate findings across 6 of 10 studies ( $n=390)$ revealed that $86.7 \%$ of patients ( $95 \%$ CI $77.5-96.0$ ) made at least 1 inhalation technique error (Figure 2a). Across the remaining 4 of 10 studies ( $n=885$ ), $76.8 \%$ of patients (95\% CI 65.8-87.9) incorrectly performed $\geq$ $20 \%$ of device use steps (Figure 2b). Further analyses were conducted to evaluate MDI device use errors with and without a spacer ( $n=352$ across 4 unique studies, and n=923 across 6 unique studies, respectively). A slightly higher proportion of patients who used a spacer made inhalation technique errors as compared to those who did not use a spacer $(82.7 \%$ [95\% CI 73.292.2] versus $78.2 \%$ [95\% CI 61.4-94.9], respectively) (Figures $3 \mathrm{a}$ and $3 \mathrm{~b}$ ). $\mathrm{I}^{2}$ values were small $(<50 \%$ ), except for patients who did not use a spacer (Figure $\left.3 \mathrm{~b} ; \mathrm{I}^{2}=78.3 \%\right)$.

\section{Step-By-Step Metered-Dose Inhaler Device Use Errors}

Eight of the 10 (80\%) studies reported error data for each device use step ( $\mathrm{n}=1105$ patients). The most frequent errors were: (a) failure to attach the inhaler to the spacer when required (based on 2 studies using MDI with a spacer, $n=24)(78.1 \%$ [95\% CI 65.3, 91.0]); (b) failure to exhale fully (and away from the inhaler) before inhalation (65.5\% [95\% CI 52.0, 78.9]); (c) failing to hold breath for $5-10$ seconds (41.9\% [95\% CI 29.8, 53.9]); (d) inhaling too fast and not deeply (39.4\% [95\% CI 26.6, 52.5]); (e) failing to exhale after inhalation (35.9\% [95\% CI 17.0, 54.8]); and (f) failing to shake the inhaler before use $(34.2 \%$ [95\% CI 30.6, 37.7]) (Figure 4). Additionally, 43.2\% (95\% CI 31.3, 55.0) of patients failed to repeat the steps for a second puff. $\mathrm{I}^{2}$ values were negligible for steps 2,3 , and 6 . For steps 5 and 7 through 12, $\mathrm{I}^{2}$ ranged from $77.9 \%$ to $98.6 \%$. 


\section{Table 1. Participant Characteristics from Studies Included in the Systematic Literature Review and Meta-Analysis}

\begin{tabular}{|c|c|c|c|c|c|c|c|}
\hline Study & $\begin{array}{c}\text { Study } \\
\text { Designa }\end{array}$ & $\begin{array}{l}\text { Patients } \\
\text { (N) }\end{array}$ & $\begin{array}{c}\text { Mean Age } \\
( \pm \text { SD/Range })\end{array}$ & $\begin{array}{l}\operatorname{Sex}^{b} \\
(N)\end{array}$ & $\begin{array}{l}\text { Low Health } \\
\text { Literacyc } \\
(\%)\end{array}$ & $\begin{array}{l}\text { Diagnosis }^{d} \\
(\mathrm{~N})\end{array}$ & $\begin{array}{c}\text { Device Type } \\
\text { (N) }\end{array}$ \\
\hline $\begin{array}{l}\text { Goodman } \\
\text { et al, } 1994^{46}\end{array}$ & CS & 59 & $38(20-81)$ & $\begin{array}{r}M(33) \\
F(26)\end{array}$ & -- & $\begin{array}{r}\text { COPD (11) } \\
\text { Asthma (48) }\end{array}$ & MDI (59) \\
\hline $\begin{array}{l}\text { Press } \\
\text { et al, } 2011^{21}\end{array}$ & $\mathrm{CS}$ & 100 & $51.7( \pm 17.4)$ & $\begin{array}{r}\text { M (27) } \\
\text { F (73) }\end{array}$ & $32 \%{ }^{h}$ & $\begin{array}{r}\text { COPD (40) } \\
\text { Asthma (60) }\end{array}$ & MDI+S (99) \\
\hline $\begin{array}{l}\text { Press } \\
\text { et al, } 2012^{22}\end{array}$ & $\mathrm{RCT}$ & $\begin{array}{l}26^{f} \\
24 g\end{array}$ & $\begin{array}{r}51( \pm 13.6) \\
56.4( \pm 19.0)\end{array}$ & $\begin{array}{r}M(8) \\
F(18) \\
M(8) \\
F(16)\end{array}$ & $\begin{array}{r}36 \%{ }^{\mathrm{i}} \\
9 \%{ }^{\mathrm{j}}\end{array}$ & $\begin{array}{r}\text { COPD (15) } \\
\text { Asthma (11) } \\
\text { COPD (15) } \\
\text { Asthma (9) }\end{array}$ & $\begin{array}{l}\text { MDI+S (26) } \\
\text { MDI+S (24) }\end{array}$ \\
\hline $\begin{array}{l}\text { Kiser } \\
\text { et al, } 2012^{39}\end{array}$ & $\mathrm{RCT}$ & $\begin{array}{l}32^{\mathrm{f}} \\
67^{\mathrm{g}}\end{array}$ & $\begin{array}{l}63(44-83) \\
63(43-84)\end{array}$ & $\begin{array}{r}\text { M (11) } \\
\text { F (21) } \\
\text { M (24) } \\
\text { F (43) }\end{array}$ & $\begin{array}{l}33 \% \\
37 \%\end{array}$ & $\begin{array}{l}\text { COPD (32) } \\
\text { COPD (67) }\end{array}$ & $\begin{array}{l}\text { MDI (32) } \\
\text { MDI (67) }\end{array}$ \\
\hline $\begin{array}{l}\text { Vanderman } \\
\text { et al, } 2015^{41}\end{array}$ & $\mathrm{PO}$ & 24 & $82(65-94)$ & M (24) & -- & $\begin{array}{l}\text { COPD (15) } \\
\text { Asthma (9) }\end{array}$ & MDI (19) \\
\hline $\begin{array}{l}\text { Press } \\
\text { et al, } 2016^{23}\end{array}$ & RCT & $\begin{array}{l}58^{f} \\
62^{g}\end{array}$ & $\begin{array}{l}49(39-57) \\
48(35-59)\end{array}$ & $\begin{array}{r}\text { M (17) } \\
\text { F (41) } \\
\text { M (15) } \\
\text { F (47) }\end{array}$ & $\begin{array}{l}20 \%{ }^{\mathrm{k}} \\
25 \% \%^{1}\end{array}$ & $\begin{array}{r}\text { COPD (22) } \\
\text { Asthma (36) } \\
\text { COPD (16) } \\
\text { Asthma (46) }\end{array}$ & $\begin{array}{l}\text { MDI+S (58) } \\
M D I+S(62)\end{array}$ \\
\hline $\begin{array}{l}\text { Press } \\
\text { et al, } 2017^{24}\end{array}$ & CS & 90 & $47.9( \pm 14.1)$ & $\begin{array}{r}\text { M (34) } \\
F(56)\end{array}$ & $17 \%^{\mathrm{m}}$ & $\begin{array}{r}\text { COPD (29) } \\
\text { Asthma (61) }\end{array}$ & MDI+S (83) \\
\hline $\begin{array}{l}\text { Melzer } \\
\text { et al, } 2017^{40}\end{array}$ & CS & 688 & -- & $\begin{array}{r}\text { M (357) } \\
\text { F (331) }\end{array}$ & $26 \%$ & COPD & MDI (616) \\
\hline $\begin{array}{l}\text { Ding } \\
\text { et al, } 2018^{49}\end{array}$ & $\mathrm{CS}$ & 30 & $61.4^{\mathrm{n}}(41-78)$ & $\begin{array}{r}\mathrm{M}(18) \\
\mathrm{F}(12)\end{array}$ & - & COPD & MDI (30) \\
\hline $\begin{array}{l}\text { Shealy } \\
\text { et al, } 2018^{50}\end{array}$ & CS & 100 & 53 & $\begin{array}{l}\text { M (39) } \\
F(54) \\
\text { NR (7) }\end{array}$ & $23 \%$ & $\begin{array}{r}\text { COPD (32) } \\
\text { Asthma (36) } \\
\text { Other (32) }\end{array}$ & MDI (100) \\
\hline Total & & 1360 & & $\begin{array}{r}1360 \\
M(615) \\
F(738) \\
\text { NR (7) }\end{array}$ & & $\begin{array}{r}1360 \\
\text { COPD (1012) } \\
\text { Asthma (312) } \\
\text { Other (36) }\end{array}$ & $\begin{array}{r}1275^{\circ} \\
\mathrm{MDI}(923) \\
\mathrm{MDI}+\mathrm{S}(352)\end{array}$ \\
\hline
\end{tabular}

\footnotetext{
${ }^{\mathrm{a}} \mathrm{RCT}=$ randomized controlled trial, $\mathrm{CS}=$ Cross-sectional, $\mathrm{PO}=$ Prospective observational;

${ }^{\mathrm{b}} \mathrm{M}=$ Male, $\mathrm{F}=$ Female, NR=No Responses;

${ }^{\mathrm{c}}$ Low health literacy was defined as having a score of $<23 / 36$ on the Short Test of Functional Health Literacy in Adults (S-TOFHLA), $\leq 6$ th grade and 7-8th grade reading level on the Assessment of Adult Literacy in Medicine-Short Form (REALM-SF), or 'always or often need assistance reading health literature' on the single-item literacy screener;

$\mathrm{d}$ Asthma diagnosis includes asthma and other obstructive pulmonary diseases and NR/other includes no responses or other illnsess;

${ }^{\mathrm{e}} \mathrm{MDI}+\mathrm{S}=\mathrm{MDI}$ with spacer;

$\mathrm{f}, \mathrm{g}$ Included pre-intervention data from the control and intervention groups, respectively;

$\mathrm{h}, \mathrm{i}, \mathrm{j}, \mathrm{k}, \mathrm{l}, \mathrm{m}$ Assessed in $71,14,11,50,52$, and 36 participants, respectively;

${ }^{n}$ Weighted mean age calculated based on the proportion of male and female;

${ }^{\circ}$ The number of device users are not equal to the number of unique patients
}

$\mathrm{COPD}=$ chronic obstructive pulmonary disease; $\mathrm{MDI}=$ metered-dose inhaler 


\section{Figure 1. Preferred Reporting Items for Systematic Reviews and Meta-Analysis Flow Chart}

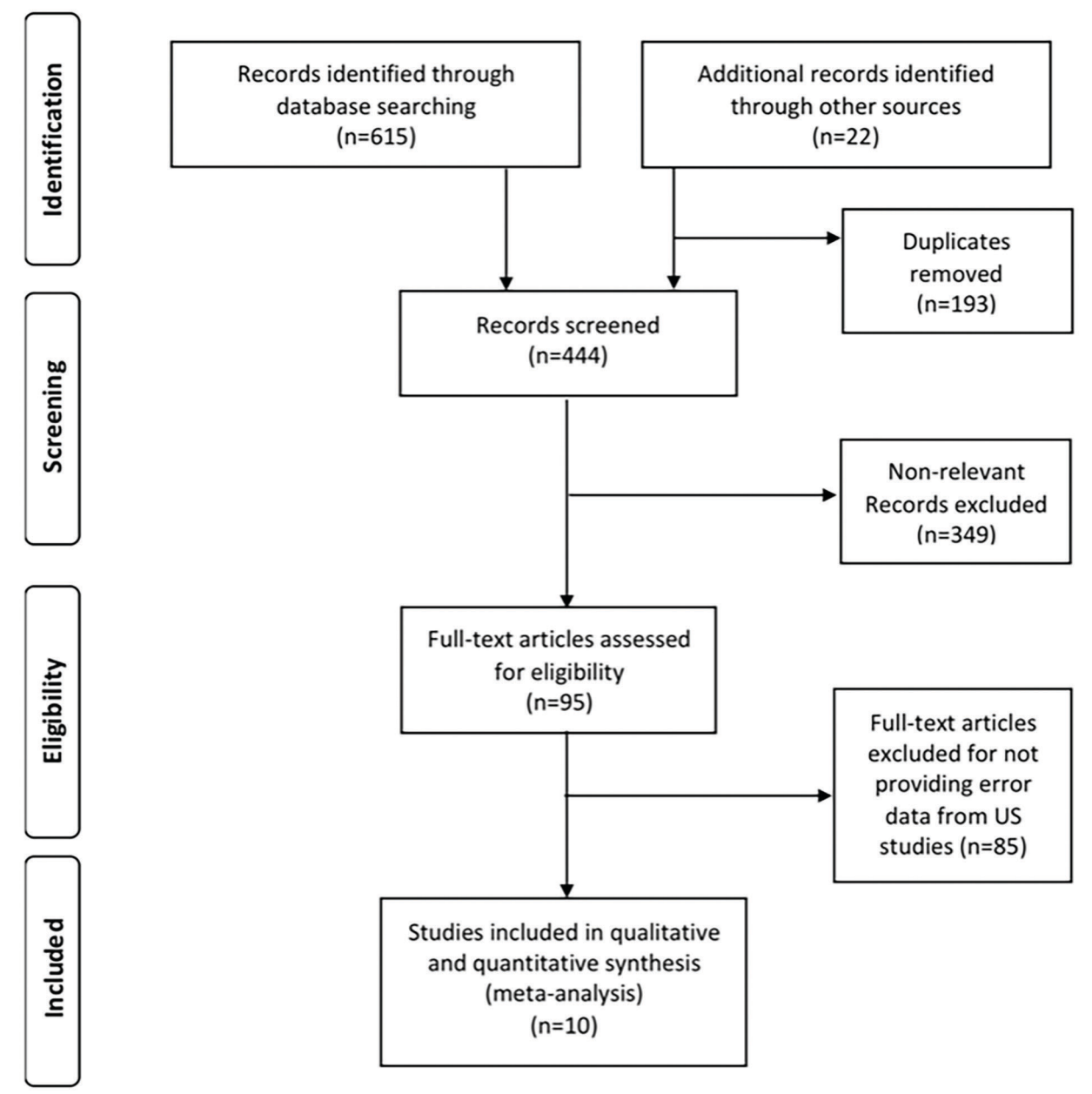

Adapted from Moher et al, $2009^{56}$

\section{Figure 2a. Meta-Analysis of Patients with at Least 1 Inhalation Technique Error Using a Metered-Dose Inhaler}

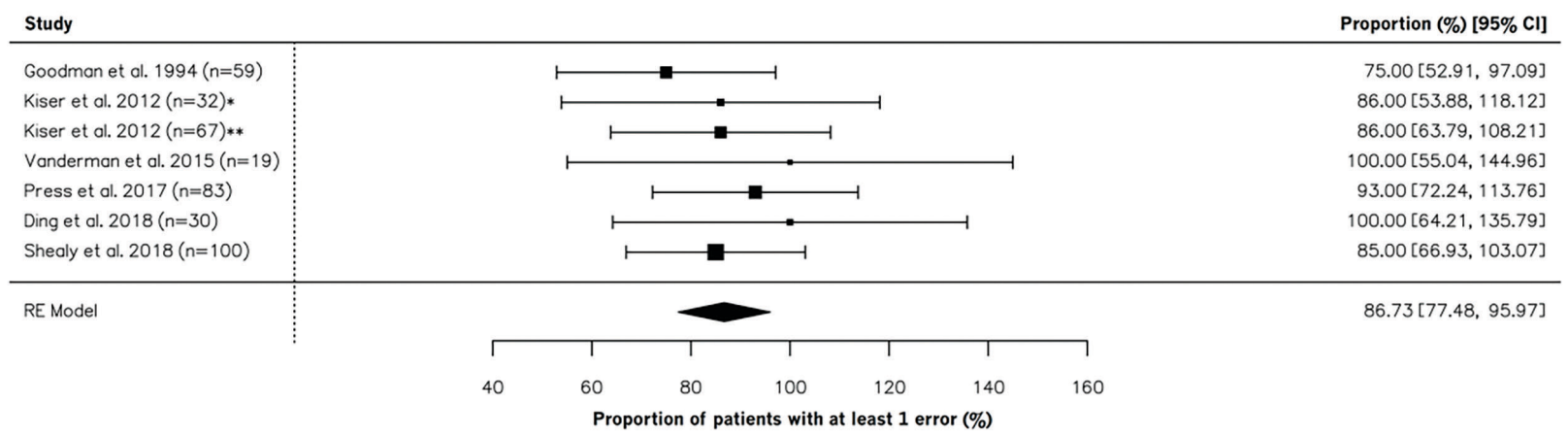

Note: *Control group and **intervention group using baseline measures. Multiple groups presented by Kiser et al resulted in 7 entries from 6 unique studies. The highest step-by-step error rate was used for Kiser et al as they only reported mean inhaler score. 

Figure 2b. Meta-analysis of Patients Who Incorrectly Performed $\geq 20 \%$
of Device Use Steps with a Metered-Dose Inhaler

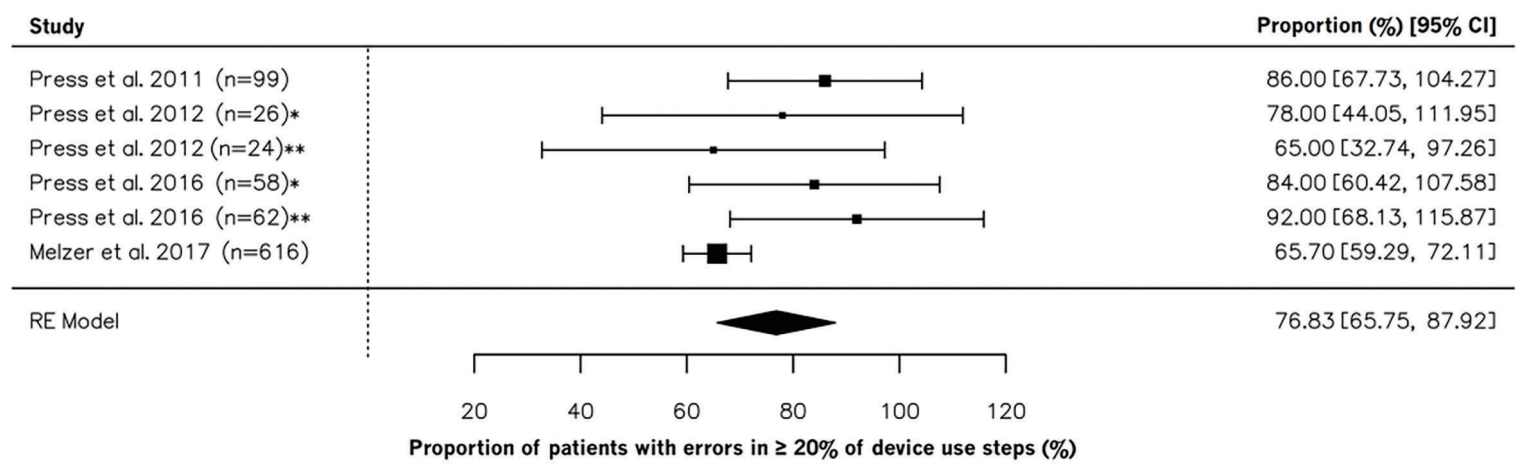

Note: *Control group and **intervention group using baseline measures. Multiple groups presented by Press et al, 2012 and 2016 resulted in 6 entries from 4 unique studies.

\section{Figure 3a. Meta-Analysis of Inhalation Technique Errors Among Patients Who Used a Metered-Dose Inhaler with a Spacer}

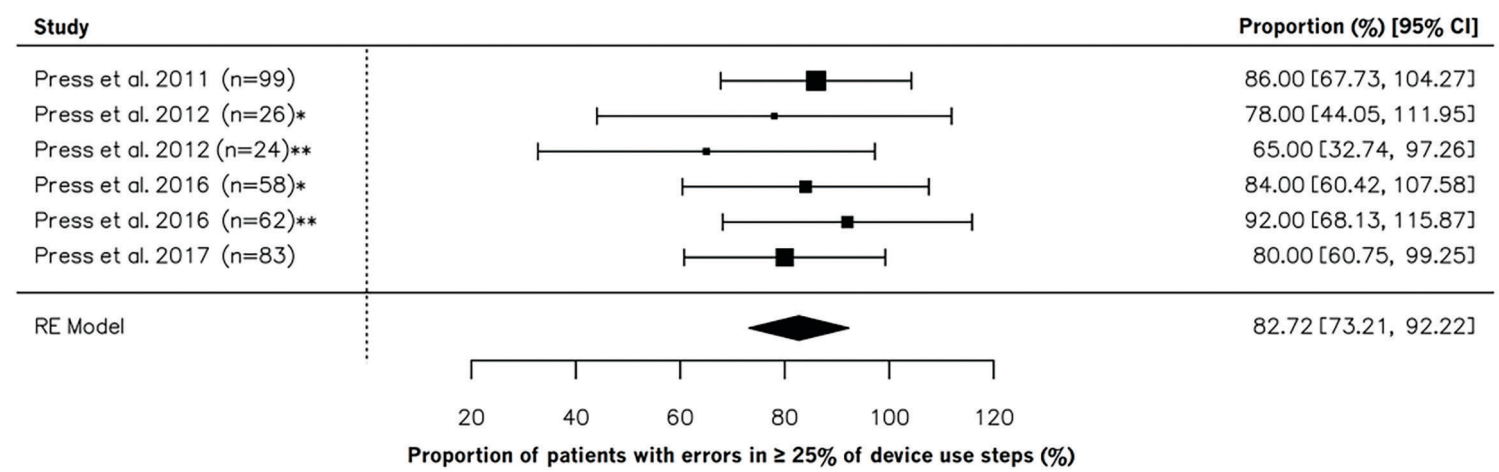

Note: *Control group and **intervention group using baseline measures. Multiple groups presented by Press et al, 2012 and 2016 resulted in 6 entries from 4 unique studies.

\section{Figure 3b. Meta-Analysis of Inhalation Technique Errors Among Patients Who Used a Metered-Dose Inhaler Without a Spacer}

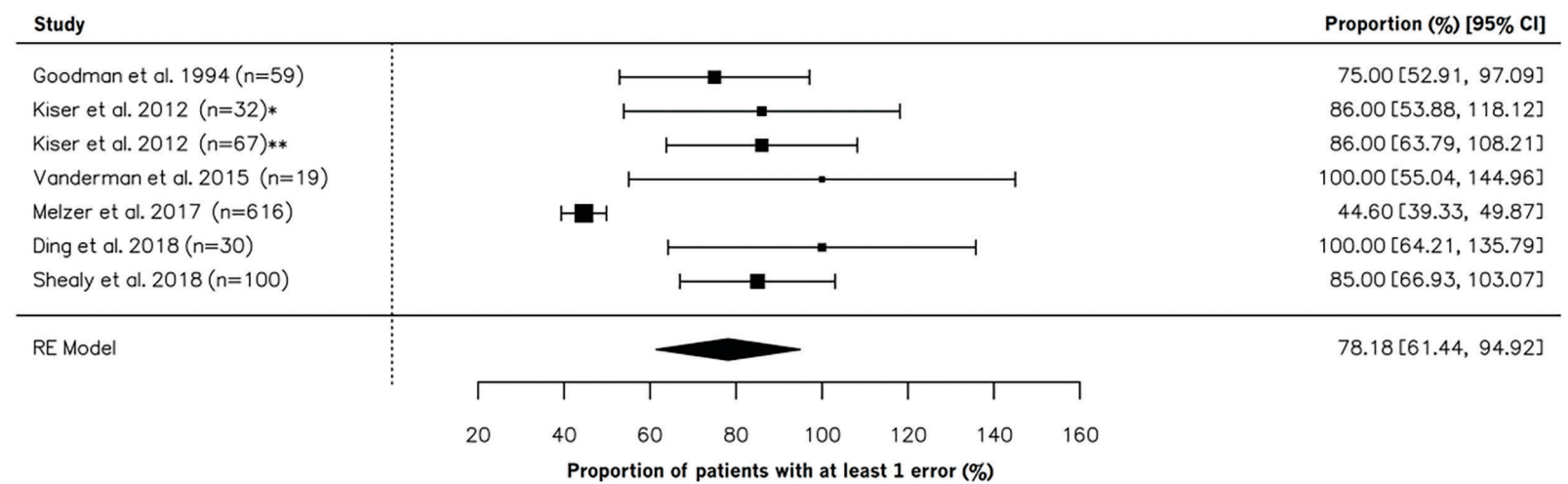

Note: ${ }^{*}$ Control group and **intervention group using baseline measures. Multiple groups presented by Kiser et al resulted in 7 entries from 6 unique studies. The highest step-by-step error rate was used for Kiser et al. as they only reported mean inhaler score. 


\section{Figure 4. Forest Plot Showing Weighted Average Percentage of Errors by Device Use Step for Metered-Dose Inhalers}

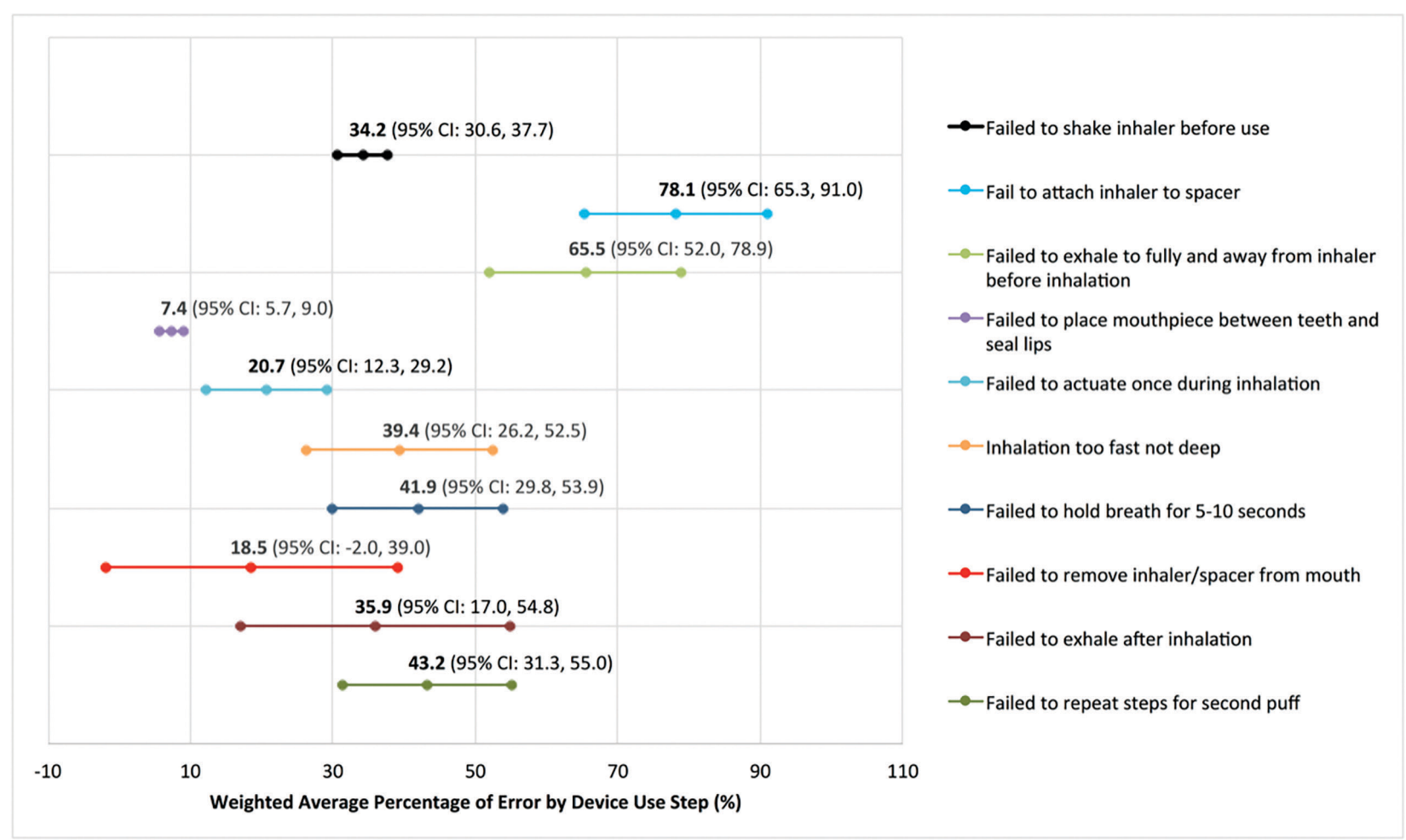

\section{Discussion}

To the best of our knowledge, this is the first SLR and MA to quantify the prevalence of MDI inhalation technique errors and identify the most problematic device use steps for U.S. adults with obstructive lung diseases. Aggregate findings across the identified studies revealed that 8 of 10 patients who used MDIs made at least 1 inhalation technique error. In addition, 7 of 10 patients incorrectly performed at least $20 \%$ of MDI device use steps.

Our results are comparable to previously reported findings on international patients. In an SLR and MA study conducted by Chrystyn et al, ${ }^{11}$ the authors found that $86.8 \%$ of patients using MDIs made at least 1 inhalation technique error, of which $45.6 \%$ were considered a critical error (defined as an error that may directly impact the effectiveness of the delivered drug). In contrast to both our findings and those reported by Chrystyn et al, Sanchis et $\mathrm{al}^{34}$ reported an average inhalation error rate of about $40 \%$ among MDI users in their MA. This lower error rate likely stemmed from
Sanchis et al's more restricted definition of errors which was limited to only device use errors related to coordination and breath-holding inhalation steps. In addition, unlike our study, Sanchis et al's study population was not limited to adults (e.g., included children with asthma).

Our results show that the most common errors were associated with coordination and breath-holding steps. We found that 2 of 3 patients had difficulty exhaling fully and away from their MDIs before inhalation. Errors that result in not emptying the lungs completely could have negative consequences on appropriately inhaling prescribed medications. We also found about 2 of 5 patients failed to hold their breath for the few seconds needed in order to ensure that the medication was successfully delivered to the lungs. This type of error can negatively impact treatment due to poor medication deposition. Moreover, 1 in 3 patients failed to inhale slowly and deeply. This type of error also adversely affects medication deposition. Other steps involved in dose preparation, such as failing to shake the inhaler before use, led to additional errors in 1 of 3 
MDI users. Collectively, our findings seem to indicate lower MDI error rates associated with coordination and breath-holding steps among U.S. patients when compared to international patients, of whom $>45 \%$ have been reported to make these types of errors in previous MA studies. ${ }^{11,34}$

We also found that a higher proportion of patients who used MDIs with a spacer made inhalation technique errors, as compared to patients who did not use a spacer. This finding was surprising and not consistent with the general reason for prescribing a spacer; that is, to facilitate inhalation technique steps that could lead to lower errors in MDI use. $8,13,57$ Our findings are also not consistent with internationallyfocused MA studies which have reported substantially lower MDI device use errors when a spacer is used. ${ }^{11,34}$ It is not clear why our findings differ. One plausible explanation is that selection bias is playing a role since U.S. clinicians tend to prescribe a spacer for an MDI for patients who are more likely to have difficulty performing inhalation steps correctly compared to patients who demonstrate greater competency using MDIs. ${ }^{13,58,59}$ Another possibility is related to the fact that all of the patients who used an MDI with a spacer came from multiple studies conducted by Press et al. It is plausible that those patients could have been from the same institution and potentially not independent samples. Yet a third plausible explanation could be the differential age distribution in the study samples, a critical factor shown to be associated with MDI device use errors and the probability of using a spacer. ${ }^{35,36}$

The predominance of errors documented across the many studies included in this SLR and MA underscores the importance of patient training and education on the proper use of MDIs. Indeed, global respiratory guidelines for both asthma and COPD suggest that participants be instructed on proper use of inhaler devices and also have their inhalation technique re-assessed at each office visit. ${ }^{13,14}$ Unfortunately, past research has shown that between $25 \%$ to $30 \%$ of patients never receive instructions on inhaler use. ${ }^{50,60}$ Moreover, up to $69 \%$ of patients say that their health care provider has never observed them using their inhalers. ${ }^{61}$ Studies have also shown that only $45 \%$ of health care providers assess device technique in every newly diagnosed patient. ${ }^{62}$ Taken together, it is not surprising that many patients report not feeling confident that they are using their inhalers correctly. ${ }^{63-65}$ Even when patients feel confident that their inhalation technique is correct, there is value in health care providers continually reassessing the patients' technique. Indeed, multiple studies have shown that the probability of patients correctly performing inhalation steps increases with the higher number of demonstrations by health care providers. $^{42,64,66}$ Clearly, educating patients on proper inhaler technique is of paramount importance in reducing the risk of inhalation errors. ${ }^{13,17, \overline{6} 6}$

Although a recent SLR of educational interventions found that $>90 \%$ of studies reported significant improvements in the patients' inhalation technique after they received training, education on device use is not an adequate enough strategy to reduce technique errors for some patients. ${ }^{37}$ For MDIs, past studies have reported persistently high rates of incorrect MDI use even after training and educational interventions. ${ }^{32,67,68}$ In real-world settings, incorrect MDI use remains challenging because compared to other types of devices, MDIs require more handbreath coordination, higher cognitive abilities to operate, the ability to hold breath, and the need to generate adequate inspiratory force. ${ }^{29}$ These types of requirements have led to some patients ceasing inhaled therapy due to the perceived complexity of using devices. ${ }^{69}$ Thus, for some patients, inhalation technique errors may be mitigated by using alternative devices, such as nebulized delivery that does not require hand-mouth coordination or breath holding for proper medication administration. Past studies have shown that many patients with difficulty using handheld inhalers have positive perceptions of nebulizer use. ${ }^{64}$ Ultimately, device features such as simplicity and ease of use, convenience, and overall experience are important to patients. ${ }^{69,70}$ Therefore, sensitizing health care providers to more carefully select inhalation devices that suit patients' abilities and preferences, while meeting their medical needs, is imperative to reducing device use errors.

Our results should be considered in light of certain study limitations. First, a relatively small number of studies met our inclusion criteria. The number of studies with data available on step-by-step device use errors was even smaller. Thus, our findings may have limited generalizability to larger populations of asthma or COPD patients. Second, there was little to no information available on the association between MDI device use errors and the clinical consequences of errors on symptom management and health outcomes. 
Third, we were unable to examine a multitude of factors that have been shown to influence the incidence of MDI device use errors, such variability in the level of training patients may have received from providers, the patient's physical or cognitive limitations, the subjectivity of the assessor's technique in evaluating patient errors, and patient-introduced bias (i.e., the Hawthorne effect). ${ }^{71}$ Fourth, we were unable to distinguish potential differences in error rates between asthma and COPD patients because the majority of the studies combined the 2 diagnoses when reporting MDI use errors. Lastly, our results on inhalation technique errors among patients who used MDIs with a spacer may have been influenced by selection bias since all of the studies were published by the same group of authors in 1 setting; therefore, the uniqueness of the study samples could not be ascertained.

\section{Conclusions}

In this SLR and MA, we found that more than 8 out of 10 patients in our sample of U.S. adults with obstructive lung diseases made at least 1 inhalation technique error using MDIs. At least 1 out of 3 patients had difficulty exhaling fully (and away) before inhalation, holding their breath, and inhaling slowly and deeply. Our findings suggest the need for ongoing patient education and consideration of alternative devices, such as nebulizers, that may mitigate technique errors by eliminating some of the inhalation steps that patients have difficulty completing.

\section{Acknowledegments}

Author contributions: The literature search was conducted by authors SC, KY and MN; variable selection and data extraction were performed by SC, $\mathrm{KY}$, and MN. Various phases of study conceptualization, data analysis and results interpretation were led by SC, BRC, CD, and MN. All authors contributed to manuscript preparation, its review and its final approval for publication. We would like to acknowledge Vaidyanathan Ganapathy, PhD, formerly with Sunovion Pharmaceuticals Inc., for his support with study conceptualization and implementation. We also extend our appreciation to Cynthia Ingrao, DNP, RN, CNM, formerly with Advance Health Solutions, for her assistance with data validation.

\section{Declaration of Interest}

SC, KY and MN are employed by Advance Health Solutions, LLC. BRC received consultation remuneration as a member of the Medical Advisory Board at Advance Health Solutions, LLC. He has also been an expert pulmonologist consultant for GlaxoSmithKline, Boehringer-Ingelheim, Astra Zeneca, Novartis, and Pulmonix. CD is employed by Sunovion Pharmaceuticals, Inc. 


\section{References}

1. Centers for Disease Control and Prevention (CDC). Asthma: data, statistics, and surveillance. CDC website. http://www.cdc. gov/asthma/asthmadata.htm.

Published September 2016. Accessed November 2018.

2. American Lung Association (ALA). How serious is COPD? ALA website. https://www.lung.org/lung-health-and-diseases/lungdisease-lookup/copd/learn-about-copd/how-serious-is-copd. html. Published March 2018. Accessed November 2018.

3. Moorman JE, Akinbami LJ, Bailey CM, et al. National surveillance of asthma: United States, 2001-2010. Vital Health Stat. 2012;3(35):1-58.

4. Mendy A, Forno E, Niyonsenga T, Carnahan R, Gasana J. Prevalence and features of asthma-COPD overlap in the United States 2007-2012. Clin Respir J. 2018;12(8):2369-2377. doi: https://doi.org/10.1111/crj.12917

5. Barnett SB, Nurmagambetov TA. Costs of asthma in the United States: 2002-2007. J Allergy Clin Immunol. 2011;127(1):145-152. doi: https://doi.org/10.1016/j.jaci.2010.10.020

6. Nurmagambetov T, Kuwahara R, Garbe P. The economic burden of asthma in the United States, 2008-2013. Ann Am Thorac Soc. 2018;15(3):348-356.

doi: https://doi.org/10.1513/AnnalsATS.201703-2590C

7. Ford ES, Murphy LB, Khaviou O, Giles WH, Croft JB. Total and state-specific medical and absenteeism costs of COPD among adults aged $\geq 18$ years in the United States for 2010 and projections through 2020. Chest. 2015;147(1):31-45. doi: https://doi.org/10.1378/chest.14-0972

8. Dolovich MB, Ahrens RC, Hess DR, et al. Device selection and outcomes of aerosol therapy: evidence-based guidelines: American College of Chest Physicians/American College of Asthma, Allergy, and Immunology. Chest. 2005;127(1):335-371. doi: https://doi.org/10.1378/chest.127.1.335

9. Pritchard JN. Industry guidance for the selection of a delivery system for the development of novel respiratory products. Expert Opin Drug Deliv. 2015;12(11):1755-1765. doi: https://doi.org/10.1517/17425247.2015.1056148

10. Levy ML, Dekhuijzen PN, Barnes PJ, et al. Inhaler technique: facts and fantasies. A view from the Aerosol Drug Management Improvement Team (ADMIT). NPJ Prim Care Respir Med. 2016;26:16017. doi: https://doi.org/10.1038/npjpcrm.2016.17

11. Chrystyn H, van der Palen J, Sharma R, et al. Device errors in asthma and COPD: systematic literature review and metaanalysis. NPJ Primary Care Respir Med. 2017;27(1):22. doi: https://doi.org/10.1038/s41533-017-0016-z

12. Braido F, Chrystyn H, Baiardini I, et al. Trying, but failing - the role of inhaler technique and mode of delivery in respiratory medication adherence. $J$ Allergy Clin Immunol Pract. 2016;4(5):823-832. doi: https://doi.org/10.1016/j.jaip.2016.03.002
13. Global Initiative for Chronic Obstructive Pulmonary Disease (GOLD). Global strategy for the diagnosis, management, and prevention of chronic obstructive pulmonary disease. GOLD website. https://goldcopd.org/gold-reports/.

Published 2018. Accessed November 2018.

14. Global Initiative for Asthma (GINA). 2018 GINA report. Global strategy for asthma management and prevention. GINA website. http://ginasthma.org/2018-gina-report-global-strategyfor-asthma-management-and-prevention/.

Published 2018. Accessed November 2018.

15. Molimard M, Raherison C, Lignot S, et al. Chronic obstructive pulmonary disease exacerbation and inhaler device handling: real-life assessment of 2935 patients. Eur Respir J. 2017;49(2):1601794. doi: https://doi. org/10.1183/13993003.01794-2016

16. Melani AS, Bonavia M, Cilenti V, et al. Gruppo Educazionale Associazione Italiana Pneumologi Ospedalieri. Inhaler mishandling remains common in real life and is associated with reduced disease control. Respir Med. 2011;105(6):930-938. doi: https://doi.org/10.1016/j.rmed.2011.01.005

17. Maricoto T, Monteiro L, Gama JMR, Correia-de-Sousa J, TabordaBarata L. Inhaler technique education and exacerbation risk in older adults with asthma or chronic obstructive pulmonary disease: a meta-analysis. J Am Geriatr Soc. 2019;67(1):57-66. doi: https://doi.org/10.1111/jgs.15602

18. Brocklebank D, Ram F, Wright J, et al. Comparison of the effectiveness of inhaler devices in asthma and chronic obstructive airways disease: a systematic review of the literature. Health Technol Assess. 2001; 5(26):1-149. doi: https://doi.org/10.3310/hta5260

19. Barrons R, Wheeler J, Woods JA. Opportunities for inhaler device selection in elderly patients with asthma or COPD. Patient Intell. 2015;7:53-65. doi: https://doi.org/10.2147/PI.S61200

20. Mulhall AM, Zafar MA, Record S, Channell H, Panos RJ. A tablet-based multimedia education tool improves provider and subject knowledge of inhaler use techniques. Respir Care. 2017;62(2):163-171. doi: https://doi.org/10.4187/respcare.05008

21. Press VG, Arora VM, Shah LM, et al. Misuse of respiratory inhalers in hospitalized patients with asthma or COPD. J Gen Intern Med. 2011;26(6):635-642.

doi: https://doi.org/10.1007/s11606-010-1624-2

22. Press VG, Arora VM, Shah LM, et al. Teaching the use of respiratory inhalers to hospitalized patients with asthma or COPD: a randomized trial. J Gen Intern Med. 2012;27(10):13171325. doi: https://doi.org/10.1007/s11606-012-2090-9

23. Press VG, Arora VM, Trela KC, et al. Effectiveness of interventions to teach metered-dose and Diskus inhaler techniques. A randomized trial. Ann Am Thorac Soc. 2016;13(6):816-824. doi: https://doi.org/10.1513/AnnalsATS.201509-603OC 
24. Press VG, Kelly CA, Kim JJ, White SR, Meltzer DO, Arora VM. Virtual teach-to-goal adaptive learning of inhaler technique for inpatients with asthma or COPD. J Allergy Clin Immunol Pract. 2017;5(4):1032-1039.

doi: https://doi.org/10.1016/j.jaip.2016.11.018

25. Dekhuijzen PNR, Vincken W, Virchow JC, et al. Prescription of inhalers in asthma and COPD: towards a rational, rapid and effective approach. Respir Med. 2013;107(12):1817-1821. doi: https://doi.org/10.1016/j.rmed.2013.09.013

26. Lavorini F, Mannini C, Chellini E. Challenges of inhaler use in the treatment of asthma and chronic obstructive pulmonary disease. EMJ Respir. 2015;3(2):98-105.

27. Rau JL. Practical problems with aerosol therapy in COPD. Respir Care. 2006;51(2):158-172.

28. Vincken W, Dekhuijzen PR, Barnes P; ADMIT Group. The ADMIT series - Issues in inhalation therapy. 4) How to choose inhaler devices for the treatment of COPD. Prim Care Respir J. 2010;19(1):10-20. doi: https://doi.org/10.4104/pcrj.2009.00062

29. Yawn BP, Colice GL, Hodder R. Practical aspects of inhaler use in the management of chronic obstructive pulmonary disease in the primary care setting. Int $J$ Chron Obstruct Pulmon Dis. 2012;7:495-502. doi: https://doi.org/10.2147/COPD.S32674

30. DePietro M, Gilbert I, Millette LA, Riebe M. Inhalation device options for the management of chronic obstructive pulmonary disease. Postgrad Med. 2018;130(1):83-97.

doi: https://doi.org/10.1080/00325481.2018.1399042

31. Crompton GK, Barnes PJ, Broeders M, et al. The need to improve inhalation technique in Europe: a report from the Aerosol Drug Management Improvement Team. Respir Med. 2006;100(9):14791494. doi: https://doi.org/10.1016/j.rmed.2006.01.008

32. Dantic DE. A critical review of the effectiveness of 'teach-back' technique in teaching COPD patients self-management using respiratory inhalers. Health Educ J. 2014;73(1):41-50. doi: https://doi.org/10.1177/0017896912469575

33. Salvi S, Gogtay J, Aggarwal B. Use of breath-actuated inhalers in patients with asthma and COPD-an advance in inhalational therapy: a systematic review. Expert Rev Respir Med. 2014;8(1):89-99.

doi: https://doi.org/10.1586/17476348.2014.854168

34. Sanchis J, Corrigan C, Levy ML, Viejo JL; ADMIT Group. Inhaler devices - from theory to practice. Respir Med. 2013;107(4):495502. doi: https://doi.org/10.1016/j.rmed.2012.12.007

35. Barbara S, Kritikos V, Bosnic-Anticevich S. Inhaler technique: does age matter? A systematic review. Eur Respir Rev. 2017;26(146);170055.

doi: https://doi.org/10.1183/16000617.0055-2017
36. Mahon J, Fitzgerald A, Glanville J, et al. Misuse and/or treatment delivery failure of inhalers among patients with asthma or COPD: a review and recommendations for the conduct of future research. Respir Med. 2017;129:98-116. doi: https://doi.org/10.1016/j.rmed.2017.05.004

37. Klijn SL, Hiligsmann M, Evers SMAA, Román-Rodríguez M, van der Molen T, van Boven JFM. Effectiveness and success factors of educational inhaler technique interventions in asthma \& COPD patients: a systematic review. NPJ Prim Care Respir Med. 2017;27(1):24. doi: https://doi.org/10.1038/s41533-017-0022-1

38. Sanchis J, Gich I, Pedersen S; ADMIT. Systematic review of errors in inhaler use: has patient technique improved over time? Chest. 2016;150(2):394-406.

doi: https://doi.org/10.1016/j.chest.2016.03.041

39. Kiser K, Jonas D, Warner Z, Scanlon K, Shilliday BB, DeWalt DA. A randomized controlled trial of a literacy-sensitive selfmanagement intervention for chronic obstructive pulmonary disease patients. J Gen Intern Med. 2012;27(2):190-195. doi: https://doi.org/10.1007/s11606-011-1867-6

40. Melzer AC, Ghassemieh BJ, Gillespie SE, et al. Patient characteristics associated with poor inhaler technique among a cohort of patients with COPD. Respir Med. 2017;123:124-130. doi: https://doi.org/10.1016/j.rmed.2016.12.011

41. Vanderman AJ, Moss JM, Bailey JC, Melnyk SD, Brown JN. Inhaler misuse in an older adult population. Consult Pharm. 2015;30(2):92-100. doi: https://doi.org/10.4140/TCP.n.2015.92

42. Bartolo K, Balzan M, Schembri EL, et al. Predictors of correct technique in patients using pressurized metered dose inhalers. BMC Pulm Med. 2017;17(1):47. doi: https://doi.org/10.1186/s12890-017-0386-6

43. Melani AS, Bonavia M, Mastropasqua E, et al. Time required to rectify inhaler errors among experienced subjects with a faulty technique. Respir Care. 2017;62(4):409-414. doi: https://doi.org/10.4187/respcare.05117

44. Vargas O, Martinez J, Ibanez M, Pena C, Santamaria M. The use of metered-dose inhalers in hospital environments. J Aerosol Med Pulm Drug Deliv. 2013;26(5):287-296. doi: https://doi.org/10.1089/jamp.2011.0940

45. Lareau SC, Hodder R. Teaching inhaler use in chronic obstructive pulmonary disease patients. J Am Acad Nurse Pract. 2012;24(2):113-120. doi: https://doi.org/10.1111/j.1745-7599.2011.00681.x

46. Goodman DE, Israel E, Rosenberg M, Johnston R, Weiss ST, Drazen JM. The influence of age, diagnosis, and gender on proper use of metered-dose inhalers. Am J Respir Crit Care Med. 1994;150(5):1256-1261. doi: https://doi.org/10.1164/ajrccm.150.5.7952549 
47. Ryan R, Hill S. How to GRADE the quality of the evidence. Cochrane Consumers and Communication Group website. http://cccrg.cochrane.org/author-resources.

Published December 2016. Accessed November 2018.

48. Wells GA, Shea B, O'Connell D, et al. The Newcastle-Ottawa Scale (NOS) for assessing the quality of non-randomised studies in meta-analyses. The Ottawa Hospital Research Institute website. http://www.ohri.ca/programs/clinical_epidemiology/ oxford.asp. Published February 2009. Accessed November 2018.

49. Ding B, Siddiqui S, DePietro M, Petersson G, Martin UJ. Inhaler usability of a pressurized metered dose inhaler and a soft mist inhaler in patients with COPD: a simulated-use study. Chron Respir Dis. 2019;16:1-9.

doi: https://doi.org/10.1177/1479972318787914

50. Shealy KM, Paradiso VC, Slimmer ML, Campbell DL, Threatt TB. Evaluation of the prevalence and effectiveness of education on metered-dose inhaler technique. Respir Care. 2017;62(7):882887. doi: https://doi.org/10.4187/respcare.05246

51. Stroup DF, Berlin JA, Morton SC, et al. Meta-analysis of observational studies in epidemiology: a proposal for reporting. Meta-analysis of Observational Studies in Epidemiology (MOOSE) group. JAMA. 2000;283(15):2008-2012. doi: https://doi.org/10.1001/jama.283.15.2008

52. Neyeloff JL, Fuchs SC, Moreira LB. Meta-analyses and Forest plots using a microsoft excel spreadsheet: step-by-step guide focusing on descriptive data analysis. BMC Res Notes. 2012;5:52. doi: https://doi.org/10.1186/1756-0500-5-52

53. Von Hippel PT. The heterogeneity statistic I2 can be biased in small meta-analyses. BMC Med Res Methodol. 2015;15:35. doi: https://doi.org/10.1186/s12874-015-0024-z

54. Higgins JP, Thompson SG, Deeks JJ, Altman DG. Measuring inconsistency in meta-analyses. BMJ. 2003;327:557-560. doi: https://doi.org/10.1136/bmj.327.7414.557

55. Huedo-Medina TB, Sánchez-Meca J, Marín-Martínez F, Botella J. Assessing heterogeneity in meta-analysis: Q statistic or I2 index? Psychol Methods. 2006;11(2):193-206.

doi: https://doi.org/10.1037/1082-989X.11.2.193

56. Moher D, Liberati A, Tetzlaff J, Altman DG; The PRISMA Group. Preferred Reporting Items for Systematic Reviews and MetaAnalyses: the PRISMA Statement.PLoS Med.2009;6(7):e1000097. doi: https://doi.org/10.1371/journal.pmed.1000097

57. Barrons R, Pegram A, Borries A. Inhaler device selection: special considerations in elderly patients with chronic obstructive pulmonary disease. Am J Health Syst Pharm. 2011;68(13):12211232. doi: https://doi.org/10.2146/ajhp100452

58. Petite SE. Characterization of chronic obstructive pulmonary disease prescribing patterns in the United States. Pulm Pharmacol Ther. 2018;49:119-122. doi: https://doi.org/10.1016/j.pupt.2018.02.003
59. Taffet GE, Donohue JF, Altman PR. Considerations for managing chronic obstructive pulmonary disease in the elderly. Clin Interv Aging. 2014;9:23-30.

doi: https://doi.org/10.2147/CIA.S52999

60. Thomas RM, Locke ER, Woo DM, et al. Inhaler training delivered by internet-based home videoconferencing improves technique and quality of life. Respir Care. 2017;62(11):1412-1422. doi: https://doi.org/10.4187/respcare.05445

61. Souza ML, Meneghini AC, Ferraz E, Vianna EO, Borges MC. Knowledge of and technique for using inhalation devices among asthma patients and COPD patients. J Bras Pneumol. 2009;35(9):824-831.

doi: https://doi.org/10.1590/S1806-37132009000900002

62. Hanania NA, Braman S, Adams SG, et al. The role of inhalation delivery devices in COPD: Perspectives of patients and health care providers. Chronic Obstr Pulm Dis. 2018;5(2):111-123. doi: https://doi.org/10.15326/jcopdf.5.2.2017.0168

63. Price D, Keininger DL, Viswanad B, Gasser M, Walda S, Gutzwiller FS. Factors associated with appropriate inhaler use in patients with COPD - lessons from the REAL survey. Int J Chron Obstruct Pulmon Dis. 2018;13:695-702. doi: https://doi.org/10.2147/COPD.S149404

64. Dhand R, Mahler DA, Carlin BW, et al. Results of a patient survey regarding COPD knowledge, treatment experiences, and practices with inhalation devices. Respir Care. 2018;63(7):833839. doi: https://doi.org/10.4187/respcare.05715

65. Luczak-Wozniak K, Dabrowska M, Domagala I, et al. Mishandling of PMDI and DPI inhalers in asthma and COPD - repetitive and non-repetitive errors. Pulm Pharmacol Ther. 2018;51:65-72. doi: https://doi.org/10.1016/j.pupt.2018.06.002

66. Usmani OS, Lavorini F, Marshall J, et al. Critical inhaler errors in asthma and COPD: a systematic review of impact on health outcomes. Respir Res. 2018:19(1):10. doi: https://doi.org/10.1186/s12931-017-0710-y

67. Ocakli B, Ozmen I, Tunçay EA, et al. A comparative analysis of errors in inhaler technique among COPD versus asthma patients. Int J Chron Obstruct Pulmon Dis. 2018; 13:2941-2947. doi: https://doi.org/10.2147/COPD.S178951

68. Aydemir Y. Assessment of the factors affecting the failure to use inhaler devices before and after training. Respir Med. 2015;109(4):451-458.

doi: https://doi.org/10.1016/j.rmed.2015.02.011

69. Kaplan A, Price D. Matching inhaler devices with patients: the role of the primary care physician. Can Respir J. 2018;2018:9473051. doi: https://doi.org/10.1155/2018/9473051 
70. Amin AN, Ganapathy V, Roughley A, Small M, Confidence in correct inhaler technique and its association with treatment adherence and health status among US patients with chronic obstructive pulmonary disease. Patient Prefer Adherence. 2017;11:1205-1212. doi: https://doi.org/10.2147/PPA.S140139

71. Wallin M, Tagami T, Chen L, Yang M, Chan HK. Pulmonary drug delivery to older people. Adv Drug Deliv Rev. 2018;135:5061. doi: https://doi.org/10.1016/j.addr.2017.11.010 